\title{
Avaliação do Programa Nacional de Alimentação Escolar: revisão da literatura
}

\author{
Evaluation of the National School Food Program: \\ review of the literature
}

Dixis Figueroa Pedraza ${ }^{1}$

Nadinne Lívia Silva de Melo ${ }^{1}$

Franciely Albuquerque Silva ${ }^{1}$

Erika Morganna Neves Araujo ${ }^{1}$

${ }^{1}$ Departamento de Enfermagem, Universidade Estadual da Paraíba. Av. das Baraúnas 351, Bodocongó. Campina Grande PB Brasil. 58109-753.

dixisfigueroa@gmail.com

\begin{abstract}
The National School Food Program (PNAE) constitutes an important strategy for the promotion of healthy eating. The objective was to perform a brief analysis of evaluative research on the PNAE. It involved a search of the literature from 2010 to 2015 in the Bireme and Scielo databases. Twelve articles were selected linked to the area, eight of which analyzed the insertion of the nutritionist in the PNAE; seven, to buy food from family farms; five, the implementation of School Food Councils; five, the compilation of menus; and four, funding destined for the PNAE. Problems in the performance of the nutritionist and the School Food Councils, on buying food from family farms and in the compilation of the menus (low fruit and vegetable content) were detected. The need for greater attention to execution of the PNAE was highlighted in order to ensure school food within guidelines that promote food and nutrition security. Further evaluation studies about the program are fundamental for the provision of subsidies to public managers for purposes of enhancing its implementation.
\end{abstract}

Key words School food, Public health, Nutrition and food programs and policies
Resumo O Programa Nacional de Alimentação Escolar (PNAE) representa uma estratégia importante de promoção da alimentação saudável. Objetivou-se realizar uma análise sumária das pesquisas avaliativas sobre o PNAE. Pesquisa bibliográfica do período de 2010 a 2015 nas bases de dados Bireme e SciELO. Foram selecionados 12 artigos vinculados à área, dos quais oito analisaram a inserção do nutricionista no PNAE; sete, a aquisição de alimentos da agricultura familiar; cinco, a implantação dos Conselhos de Alimentação Escolar; cinco, a execução dos cardápios; e quatro, os recursos financeiros destinados ao PNAE. Apontam-se problemas na atuação do nutricionista e dos Conselhos de Alimentação Escolar, na aquisição de alimentos da agricultura familiar e na composição dos cardápios (baixo conteúdo de frutas e hortaliças). Destaca-se a necessidade de maior atenção relacionada à execução do PNAE, de maneira a garantir uma alimentação escolar dentro de princípios que promovam a segurança alimentar e nutricional. Novos estudos avaliativos sobre o Programa são fundamentais para o fornecimento de subsidios aos gestores públicos com fins de aprimorar a sua execução.

Palavras-chave Alimentação escolar, Saúde pública, Programas e políticas de nutrição e alimentação 


\section{Introdução}

A alimentação escolar constitui um direito dos estudantes e dever do Estado 1 . Para a garantia desse direito, foi instituído na década de 50 o Programa Nacional de Alimentação Escolar (PNAE) com o objetivo de "contribuir para o crescimento e o desenvolvimento biopsicossocial, a aprendizagem, o rendimento escolar e a formação de hábitos alimentares saudáveis dos alunos de toda a educação básica pública, por meio de ações de educação alimentar e nutricional e da oferta de refeições que cubram as suas necessidades nutricionais durante o período letivo"'. O PNAE se destaca por ser um dos maiores programas do mundo a abranger a alimentação escolar contemplando o Direito Humano à Alimentação Adequada e a Segurança Alimentar e Nutricional ${ }^{3-5}$.

O PNAE passou por mudanças significativas desde sua criação, sobretudo no decorrer das últimas décadas em que sobressaem avanços importantes em seus aspectos técnicos e operacionais. A descentralização financeira e de gestão, iniciada na década de 1980, possibilitou aos estados e municípios uma maior eficácia de suas ações e a inserção da participação social como peça fundamental para o controle e fiscalização da execução do programa através dos Conselhos de Alimentação Escolar (CAE). A partir de então, o PNAE mostrou-se engajado em contribuir para uma alimentação condizente com a cultura de cada região, buscando melhorias na aceitação por parte do alunado e, concomitantemente, o sucesso de seu objetivo ${ }^{4,6}$.

Para esses fins, as exigências de execução do Programa encontram-se detalhadas na Lei que o rege $^{2}$ e em inúmeras resoluções lançadas nas últimas décadas em busca do aperfeiçoamento da alimentação escolar ${ }^{7-10}$. Ao não serem cumpridas tais exigências corre-se o risco de que maus hábitos alimentares sejam inseridos na fase escolar e perpetuados ao longo da vida dos alunos beneficiados $^{11}$. A alimentação escolar ofertada de forma irregular direciona os estudantes a complementarem a merenda com alimentos de baixo teor nutricional, levados de casa ou comercializados nas cantinas das próprias escolas, competindo com a alimentação oferecida ${ }^{12}$.

As pesquisas sobre a avaliação do PNAE, em suas diferentes faces, são importantes para que se possa ter um feedback a respeito da execução do programa. O presente estudo tem como objetivo realizar uma análise sumária das pesquisas avaliativas sobre o Programa Nacional de Alimentação Escolar.

\section{Métodos}

Trata-se de uma revisão da literatura sobre estudos avaliativos do PNAE. Os estudos foram identificados nas bases de dados Bireme (Centro Latino-Americano e do Caribe de Informação em Ciências da Saúde) e SciELO (Scientific Electronic Library Online). A busca, realizada em 01/02/16, considerou todos os documentos contendo a combinação dos descritores "Programas e Políticas de Nutrição e Alimentação" e "Alimentação Escolar", cruzados entre si utilizando o operador booleano "AND", limitando-se a estudos publicados entre 2010 e 2015. A escolha desse período justifica-se pela publicação, em 2009, do Marco Legal do PNAE². Para o cômputo do total de estudos identificados, foi verificada a duplicação dos mesmos nas bases de dados, sendo cada artigo contabilizado somente uma vez.

Os estudos identificados foram submetidos a processo de triagem eliminando-se, por meio da leitura dos títulos e resumos estudos em outros países que não o Brasil; monografia, dissertação e tese; artigos de revisão; e estudos sobre avaliações em saúde no contexto escolar que não consideraram os aspectos normativos do PNAE. Os registros elegidos, após o processo de triagem, foram submetidos a processo de diferenciação por meio da leitura e a análise criteriosa do texto completo, excluindo-se os artigos que foram desenvolvidos fora do contexto escolar.

Os artigos incluídos foram organizados segundo o(s) parâmetro(s) que consideraram nas suas análises. Assim, as avaliações foram sumarizadas para as seguintes categorias: situação dos profissionais (nutricionistas e merendeiras) inseridos no PNAE, aquisição de gêneros alimentícios da agricultura familiar, execução dos cardápios, implantação dos CAE, atuação intersetorial e pedagógica, recursos financeiros destinados ao Programa e tipo de gestão.

As informações selecionadas nos artigos para sua caracterização foram: autor e ano de publicação, objetivos do estudo, método (tipo de estudo), esfera(s) avaliada(s) do PNAE e principais resultados.

\section{Resultados}

O fluxo relacionado à identificação e seleção dos artigos encontra-se na Figura 1. Inicialmente, foram identificados 153 artigos, desses, 10 registros estavam duplicados. Após as análises dos títulos e resumos, foram excluídos 87 registros. Com a 


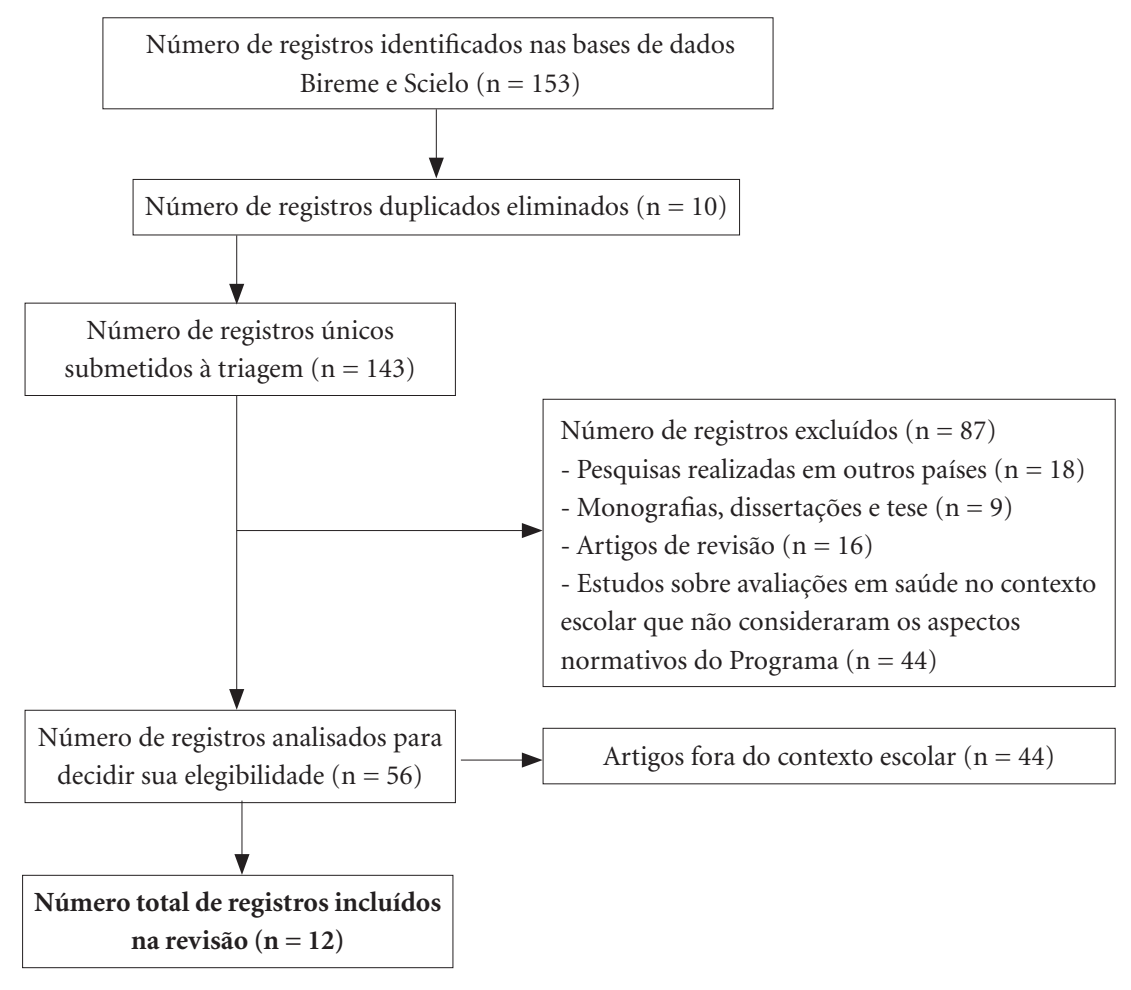

Figura 1. Fluxograma das fases de identificação, triagem e seleção de artigos sobre a avaliação do Programa Nacional de Alimentação Escolar.

leitura dos artigos na íntegra, foram incluídos 12 que adequadamente preenchiam os critérios de inclusão.

Conforme caracterização geral dos estudos no Quadro 1, dos 12 artigos incluidos ${ }^{3-6,13-20}$, dois foram definidos como pesquisa avaliativa ${ }^{13,16}$, seis como estudos transversais ${ }^{3,4,6,14,15,20}$, um de intervenção ${ }^{17}$ e três ensaios críticos ${ }^{5,18,19}$.

O Quadro 2 mostra os principais resultados dos estudos conforme categorias consideradas nas avaliações. Dos oito artigos que analisaram a situação dos nutricionistas inseridos no $\mathrm{PNAE}^{4-}$ 6,13,16-18,20, quatro ${ }^{4,5,17,18}$ relataram o aumento do cadastramento desses profissionais no PNAE e outros cinco $^{4,13,16,18,20}$ a insuficiência. $O$ único artigo que versou sobre a atuação das merendeiras apontou a atuação de um profissional por escola ${ }^{4}$.

A aquisição de gêneros alimentícios da agricultura familiar foi abordada em sete arti$\operatorname{gos}^{5,6,13,14,17,19,20}$. Os resultados apresentados apontam que essa não é, ainda, uma prática generalizada, com baixos índices em algumas localidades.
Cinco estudos avaliaram a execução dos cardápios ${ }^{6,13,15,16,20}$. Dois desses trabalhos ${ }^{6,15}$ relataram que há, no geral, boa aceitação da alimentação oferecida, enquanto a baixa quantidade de frutas e hortaliças na composição dos cardápios foi relatada em três estudos ${ }^{13,16,20}$.

Aspectos sobre a implantação dos CAE foram tratados em cinco artigos ${ }^{3,6,13,16,17}$. Em todos eles os pesquisadores constataram que os Conselhos não são efetivados de acordo com a Lei $11.947^{2}$.

Dois artigos ${ }^{13,16}$ abordaram a atuação intersetorial e pedagógica. Segundo os resultados desses estudos, a articulação e o desenvolvimento de projetos educativos não constitui uma prática rotineira no contexto do PNAE.

Os recursos financeiros destinados ao Programa foram abordados em quatro artigos ${ }^{4,5,13,16}$, mostrando-se resultados satisfatórios em relação ao repasse financeiro e à sua utilização. Os estu$\operatorname{dos}^{4,13}$ que enfocaram o tipo de gestão destacaram a centralização municipal do PNAE. 
Quadro 1. Características dos estudos sobre a avaliação do Programa Nacional de Alimentação Escolar, publicados como artigos científicos entre 2010 e 2015: caracterização geral.

\begin{tabular}{|c|c|c|c|}
\hline Autor, ano & Objetivos & Método & $\operatorname{Esfera}(s)$ avaliada(s) \\
\hline $\begin{array}{l}\text { Gabriel et al. } \\
2015^{13}\end{array}$ & $\begin{array}{l}\text { Avaliar a gestão municipal do PNAE nas três } \\
\text { capitais da região Sul do Brasil }\end{array}$ & $\begin{array}{l}\text { Pesquisa } \\
\text { avaliativa }\end{array}$ & $\begin{array}{l}\text { - CAE } \\
\text { - Nutricionistas } \\
\text { - Recursos } \\
\text { - Gestão municipal } \\
\text { - Uso de alimentos provenientes } \\
\text { da agricultura familiar } \\
\text { - Cardápios } \\
\text { - Atuação intersetorial } \\
\text { - Atuação pedagógica }\end{array}$ \\
\hline $\begin{array}{l}\text { Gonçalves et } \\
\text { al. } 2015^{14}\end{array}$ & $\begin{array}{l}\text { Caracterizar o processo de compra de } \\
\text { alimentos da agricultura familiar e comparar } \\
\text { a qualidade dos cardápios antes e após a } \\
\text { implantação da Lei 11.947/09 }\end{array}$ & Transversal & $\begin{array}{l}\text { - Uso de alimentos provenientes } \\
\text { da agricultura familiar }\end{array}$ \\
\hline $\begin{array}{l}\text { Cunha et al. } \\
2014^{15}\end{array}$ & $\begin{array}{l}\text { Avaliar a composição nutricional e descrever } \\
\text { a aceitabilidade de preparações regionais } \\
\text { servidas aos estudantes de escolas públicas de } \\
\text { áreas rurais e urbanas }\end{array}$ & $\begin{array}{l}\text { Transversal } \\
\text { descritivo }\end{array}$ & - Cardápios \\
\hline $\begin{array}{l}\text { Gabriel et al. } \\
2014^{16}\end{array}$ & $\begin{array}{l}\text { Avaliar a gestão municipal do PNAE nos } \\
\text { maiores municípios de Santa Catarina, Brasil }\end{array}$ & $\begin{array}{l}\text { Pesquisa } \\
\text { avaliativa }\end{array}$ & $\begin{array}{l}\text { - CAE } \\
\text { - Nutricionistas } \\
\text { - Cardápios } \\
\text { - Recursos } \\
\text { - Atuação intersetorial } \\
\text { - Atuação pedagógica }\end{array}$ \\
\hline $\begin{array}{l}\text { Gabriel et al. } \\
2013^{3}\end{array}$ & $\begin{array}{l}\text { Avaliar os CAE dos municípios do Estado de } \\
\text { Santa Catarina }\end{array}$ & Transversal & - CAE \\
\hline $\begin{array}{l}\text { Machado et } \\
\text { al. } 2013^{4}\end{array}$ & $\begin{array}{l}\text { Caracterizar o PNAE no Estado de Santa } \\
\text { Catarina }\end{array}$ & $\begin{array}{l}\text { Transversal } \\
\text { exploratório }\end{array}$ & $\begin{array}{l}\text { - Nutricionistas } \\
\text { - Recursos } \\
\text { - Gestão municipal } \\
\text { - Merendeiras }\end{array}$ \\
\hline $\begin{array}{l}\text { Peixinho } \\
2013^{5}\end{array}$ & $\begin{array}{l}\text { Realizar um relato do gestor nacional do } \\
\text { PNAE, com ênfase no período de } 2003 \text { a } 2010\end{array}$ & Ensaio crítico & $\begin{array}{l}\text { - Nutricionistas } \\
\text { - Uso de alimentos provenientes } \\
\text { da agricultura familiar } \\
\text { - Recursos } \\
\end{array}$ \\
\hline $\begin{array}{l}\text { Bandeira et } \\
\text { al. } 2013^{6}\end{array}$ & $\begin{array}{l}\text { Analisar os pareceres dos CAE de todo o Brasil } \\
\text { sobre a execução do PNAE }\end{array}$ & $\begin{array}{l}\text { Transversal } \\
\text { descritivo }\end{array}$ & $\begin{array}{l}\text { - CAE } \\
\text { - Nutricionistas } \\
\text { - Uso de alimentos provenientes } \\
\text { da agricultura familiar } \\
\text { - Cardápios }\end{array}$ \\
\hline $\begin{array}{l}\text { Bezerra et al. } \\
2013^{17}\end{array}$ & $\begin{array}{l}\text { Contribuir para o desenvolvimento de ações } \\
\text { de promoção da aquisição de produtos } \\
\text { da agricultura familiar em Territórios da } \\
\text { Cidadania do País }\end{array}$ & Intervenção & $\begin{array}{l}\text { - CAE } \\
\text { - Nutricionistas } \\
\text { - Uso de alimentos provenientes } \\
\text { da agricultura familiar }\end{array}$ \\
\hline $\begin{array}{l}\text { Chaves et al. } \\
2013^{18}\end{array}$ & $\begin{array}{l}\text { Discutir aspectos relacionados à evolução do } \\
\text { nutricionista ao longo dos anos }\end{array}$ & Ensaio crítico & - Nutricionistas \\
\hline $\begin{array}{l}\text { Saraiva et al. } \\
2013^{19}\end{array}$ & $\begin{array}{l}\text { Apresentar um panorama da compra de } \\
\text { alimentos provenientes da agricultura familiar, } \\
\text { analisando o seu cumprimento frente às novas } \\
\text { diretrizes de execução do PNAE }\end{array}$ & Ensaio crítico & $\begin{array}{l}\text { - Uso de alimentos provenientes } \\
\text { da agricultura familiar }\end{array}$ \\
\hline $\begin{array}{l}\text { Gabriel et al. } \\
2012^{20}\end{array}$ & $\begin{array}{l}\text { Refletir sobre o planejamento dos cardápios } \\
\text { do PNAE e apresentar o procedimento em } \\
\text { Florianópolis e Belém }\end{array}$ & $\begin{array}{l}\text { Transversal } \\
\text { descritivo }\end{array}$ & $\begin{array}{l}\text { - Nutricionistas } \\
\text { - Uso de alimentos provenientes } \\
\text { da agricultura familiar } \\
\text { - Cardápios }\end{array}$ \\
\hline
\end{tabular}

CAE: Conselho de Alimentação Escolar; PNAE: Programa Nacional de Alimentação Escolar. 
Quadro 2. Características dos estudos sobre a avaliação do Programa Nacional de Alimentação Escolar, publicados como artigos científicos entre 2010 e 2015: principais resultados.

\begin{tabular}{|c|c|}
\hline Autor, ano & Principais resultados \\
\hline \multicolumn{2}{|c|}{ Situação dos profissionais (nutricionistas e merendeiras) inseridos no Programa } \\
\hline Gabriel et al. $2015^{13}$ & - Quadro inadequado de nutricionistas nas três capitais \\
\hline Gabriel et al. $2014^{16}$ & $\begin{array}{l}\text { - Apenas três municípios com quadro adequado de nutricionistas } \\
\text { - Visitas mensais dos nutricionistas às escolas em apenas cinco municípios }\end{array}$ \\
\hline Machado et al. $2013^{4}$ & $\begin{array}{l}\text { - 91,7\% dos municípios com nutricionista como responsável técnico } \\
\text { - Uma merendeira por escola em cada município, totalizando até } 10 \text { profissionais em } \\
\text { prática }\end{array}$ \\
\hline Peixinho $2013^{5}$ & $\begin{array}{l}\text { - 2003: 12\% dos nutricionistas atuando nos estados e municípios } \\
\text { - 2011: 82\% dos municípios do Brasil com cobertura de nutricionistas }\end{array}$ \\
\hline Bandeira et al. $2013^{6}$ & $\begin{array}{l}\text { - 40,2\% dos pareceres indicando o nutricionista como responsável pela elaboração dos } \\
\text { cardápios } \\
\text { - 25,9\% dos pareceres indicando a atuação do nutricionista da aquisição, preparação e } \\
\text { distribuição da alimentação }\end{array}$ \\
\hline Bezerra et al. $2013^{17}$ & $\begin{array}{l}\text { - 27\% dos municípios que não possuíam nutricionista efetivaram contratos com } \\
\text { profissionais }\end{array}$ \\
\hline Gabriel et al. $2012^{20}$ & $\begin{array}{l}\text { - Florianópolis: } 12 \text { nutricionistas para } 27 \text { mil alunos } \\
\text { - Belém: } 3 \text { nutricionistas para } 70 \text { mil alunos }\end{array}$ \\
\hline \multicolumn{2}{|c|}{ Uso de alimentos provenientes da agricultura familiar } \\
\hline Gabriel et al. $2015^{13}$ & - 30\% dos recursos do FNDE, em 2011 \\
\hline $\begin{array}{l}\text { Gonçalves et al. } \\
2015^{14}\end{array}$ & $\begin{array}{l}\text { - Compra relatada em } 22,2 \% \text { dos municípios, destinando-se mais de } 30 \% \text { dos recursos } \\
\text { do FNDE }\end{array}$ \\
\hline Peixinho $2013^{5}$ & - Compra relatada em 54\% dos estados e municípios \\
\hline Bandeira et al. $2013^{6}$ & - Compra relatada em apenas $4,9 \%$ dos pareceres \\
\hline Bezerra et al. $2013^{17}$ & - 14\% dos gestores passaram a apoiar a aquisição de alimentos da agricultura familiar \\
\hline Saraiva et al. $2013^{19}$ & $\begin{array}{l}\text { - 47,4\% dos municípios aderiram à compra de alimentos da agricultura familiar } \\
\text { - Percentual de compras: maior na Região Sul }(71,3 \%) \text { e menor na Região Centro-Oeste } \\
(35,3 \%) \\
\text { - 21,1\% dos municípios justificaram a falta de adesão à agricultura familiar pela } \\
\text { inviabilidade de fornecimento regular e constante }\end{array}$ \\
\hline Gabriel et al. $2012^{20}$ & - Inexistência do procedimento nas duas cidades, no ano de 2010 \\
\hline \multicolumn{2}{|c|}{ Execução dos cardápios } \\
\hline Gabriel et al. $2015^{13}$ & $\begin{array}{l}\text { - Frutas e hortaliças: sem presença diária em uma das três capitais } \\
\text { - Itens controlados (salsicha/linguiça, margarina, achocolatado e pudim): oferta inferior } \\
\text { a quatro vezes/mês } \\
\text { - Alimentos típicos regionais: frequência semanal ou mensal } \\
\text { - Deficiências relacionadas ao cálculo dos valores nutricionais }\end{array}$ \\
\hline Cunha et al. $2014^{15}$ & $\begin{array}{l}\text { - Os dez pratos testados atenderam parcialmente as recomendações de macronutrientes } \\
\text { exigidas pela legislação } \\
\text { - Cinco dos pratos tiveram aceitabilidade maior que } 85 \% \\
\text { - } 90 \% \text { dos pratos foram classificados como "gostei" e "adorei" de acordo com a escala } \\
\text { hedônica facial utilizada } \\
\text { - Cinco pratos atenderam em } 100 \% \text { as recomendações de vitamina C }\end{array}$ \\
\hline Gabriel et al. $2014^{16}$ & $\begin{array}{l}\text { - 80\% dos cardápios respeitavam a cultura alimentar, porém nenhum tinha informações } \\
\text { sobre os hábitos alimentares dos estudantes } \\
\text { - Apenas três municípios com a inclusão diária de frutas e hortaliças } \\
\text { - Apenas seis municípios com informações nucionais dos cardápios }\end{array}$ \\
\hline Bandeira et al. $2013^{6}$ & $\begin{array}{l}\text { - 52,0\% de aceitação dos cardápios } \\
\text { - 10,0\% dos cardápios atendendo às necesdades nutricionais preconizadas }\end{array}$ \\
\hline Gabriel et al. $2012^{20}$ & - Frutas e hortaliças: baixa frequência em Belém, presença diária em Florianópolis \\
\hline
\end{tabular}


Quadro 2. continuação

\begin{tabular}{|c|c|}
\hline Autor, ano & $\begin{array}{r}\text { Principais resultados } \\
\end{array}$ \\
\hline \multicolumn{2}{|c|}{ Implantação do Conselho de Alimentação Escolar (CAE) } \\
\hline Gabriel et al. $2015^{13}$ & - Pouco atuante nas três capitais \\
\hline Gabriel et al. $2014^{16}$ & $\begin{array}{l}\text { - Somente dois CAE realizaram } \geq 10 \text { reuniões/ano com quórum (média de três reuniões/ } \\
\text { ano) } \\
\text { - Somente três CAE deliberaram sobre aspectos do Programa }\end{array}$ \\
\hline Gabriel et al. $2013^{3}$ & $\begin{array}{l}\text { - 95,4\% dos CAE relataram a análise da prestação de contas como a principal atribuição } \\
\text { executada } \\
\text { - 41,1\% dos CAE relataram o acompanhamento da aquisição de alimentos como a } \\
\text { atividade menos executada } \\
\text { - 10\% dos CAE referiram acompanhar o Programa somente nas escolas de funcionamento } \\
\text { - 96,1\% dos conselheiros mencionaram o nutricionista como o responsável técnico pela } \\
\text { elaboração dos cardápios } \\
\text { - 64,2\% dos conselheiros referiram que o CAE participa da elaboração dos cardápios }\end{array}$ \\
\hline Bandeira et al. $2013^{6}$ & $\begin{array}{l}\text { - 12,6\% dos CAE informaram inconformidades na execução do Programa } \\
\text { - 59,1\% dos CAE informaram maior frequência para a análise da prestação de contas no } \\
\text { exercício do controle social do Programa }\end{array}$ \\
\hline Bezerra et al. $2013^{17}$ & $\begin{array}{l}\text { - 75\% dos municípios em situação adequada } \\
\text { - Redução de aproximadamente 20\% no número de municípios com CAE válido } \\
\text { - Aumento do número de municípios com CAE diligenciado ou em análise }\end{array}$ \\
\hline \multicolumn{2}{|c|}{ Atuação intersetorial e pedagógica } \\
\hline Gabriel et al. $2015^{13}$ & $\begin{array}{l}\text { - Os três municípios relataram articulação do Programa com o setor saúde } \\
\text { - Apenas uma capital relatou a existência de projetos educativos que envolvessem toda a } \\
\text { rede }\end{array}$ \\
\hline Gabriel et al. $2014^{16}$ & $\begin{array}{l}\text { - Somente um município relatou articulação do Programa com o setor saúde } \\
\text { - Nenhum município relatou possuir rotina de encaminhamento de escolares para as } \\
\text { unidades de saúde } \\
\text { - Nove municípios relataram inexistência de projetos educativos }\end{array}$ \\
\hline \multicolumn{2}{|c|}{ Recursos financeiros e tipo de gestão } \\
\hline Gabriel et al. $2015^{13}$ & $\begin{array}{l}\text { - Investimento federal com contrapartida municipal, com melhor situação em } \\
\text { Florianópolis } \\
\text { - Florianópolis e Porto Alegre: gestão municipal centralizada } \\
\text { - Curitiba: gestão terceirizada }\end{array}$ \\
\hline Gabriel et al. $2014^{16}$ & $\begin{array}{l}\text { - Cinco municípios superaram o porcentual desejável }(>50 \%) \text { de investimento em } \\
\text { alimentos da entidade executora em relação ao recurso federal } \\
\text { - } 40 \% \text { dos municípios referiram refeitórios adequados na rede }\end{array}$ \\
\hline Machado et al. $2013^{4}$ & $\begin{array}{l}\text { - 21,6\% dos municípios apresentaram um custo médio por refeição inferior ao repasse } \\
\text { do FNDE } \\
\text { - 97,7\% dos municípios possuía gestão centralizada do Programa }\end{array}$ \\
\hline Peixinho $2013^{5}$ & $\begin{array}{l}\text { - 2003: 954,2 milhões de reais para atender 37,3 milhões de alunos } \\
\text { - 2011: } 3 \text { bilhões de reais para um total de 45,6 milhões de alunos atendidos }\end{array}$ \\
\hline
\end{tabular}

FNDE: Fundo Nacional de Desenvolvimento da Educação.

\section{Discussão}

Os benefícios da alimentação adequada, rica em frutas, hortaliças, cereais integrais e fibras, incluem a promoção da saúde e a proteção de disfunções orgânicas ${ }^{21,22}$. Na idade escolar, a alimentação saudável desempenha um papel decisivo para o crescimento e o desenvolvimento, em função do acelerado processo de maturação biológica e psicomotora ${ }^{23}$. Assim, a formação de hábitos alimentares saudáveis é essencial durante o período escolar, para o qual estratégias de educação alimentar e nutricional são necessárias e a escola deve promovê-las ${ }^{24}$.

É nesse contexto que o PNAE propõe a realização de ações de educação alimentar e nutricional e a oferta de refeições que cubram as necessidades nutricionais do alunado durante o 
período letivo ${ }^{8}$. No entanto, o que aponta a literatura é que o funcionamento do Programa está aquém do recomendado no que diz respeito à oferta de refeições saudáveis ${ }^{2}$, em várias localidades do país. Observou-se, por meio dos resultados, baixa quantidade de frutas e hortaliças na composição dos cardápios oferecidos aos escolares $^{16,20}$, circunstanciado, muito possivelmente, ao planejamento inadequado dos cardápios, cuja responsabilidade cabe ao profissional nutricionista devidamente habilitado ${ }^{2,12}$. Tais achados são motivos de preocupação, em virtude da crescente prevalência de sobrepeso e obesidade entre os escolares brasileiros 5 . Assim, considerando que a alimentação escolar apresenta boa aceitação, segundo os resultados deste estudo e de revisão anterior $^{25}$, a alimentação oferecida deve ser pensada em termos de adoção de hábitos alimentares adequados que contribuam para o crescimento e desenvolvimento biopsicossocial dos beneficiados, como pautado na concepção do Programa ${ }^{8}$. Nesse sentido, o processo de educação alimentar e nutricional deve compreender o debate de todas as dimensões envolvidas: econômica, social e cultural ${ }^{26}$.

No que se refere ao atendimento das necessidades nutricionais, o Programa preconiza que os cardápios das escolas atendam, pelo menos, $30 \%$ das mesmas quando oferecidas duas refeições e 20\% quando oferecida uma refeição em período parcial ${ }^{8}$. Entretanto, ao se analisar os pareceres dos CAE de todo o Brasil sobre a execução do PNAE, observou-se que apenas $10 \%$ dos documentos analisados apontavam para o cumprimento desse parâmetro ${ }^{6}$. Essa inadequação é preocupante, uma vez que pode comprometer o estado nutricional dos escolares, levando a estados carenciais, os quais, por sua vez, podem aumentar a suscetibilidade das crianças a diarreias e infecções, além der comprometer a maturação do sistema nervoso, visual, mental e intelectual. O alcance do percentual proposto pelo Programa é uma ação importante para contribuir com a adequação nutricional das crianças brasileiras frequentadoras da rede pública de ensino ${ }^{27}$.

A fim de cumprir com seus objetivos, propõe-se que o nutricionista seja responsável técnico pela execução do Programa ${ }^{8}$. O nutricionista é considerado o profissional habilitado para desenvolver as atividades de planejamento, coordenação, direção, supervisão e avaliação quanto à alimentação escolar ${ }^{28}$. Nesse sentido, o Conselho Federal de Nutricionistas estabelece parâmetros mínimos de referência especificados a seguir, por entidade executora, para a educação básica, com carga horária técnica mínima semanal de 30 horas: até 500 alunos (1 responsável técnico), 501 a 1000 alunos (1 responsável técnico e um quadro técnico), 1001 a 2500 alunos (1 responsável técnico e dois quadro técnico) 2501 a 5000 alunos (1 responsável técnico e três quadro técnico), acima de 5000 alunos (1 responsável técnico, três quadro técnico e um quadro técnico a cada fração de 2500 alunos ${ }^{29}$. O não atendimento desses parâmetros pode levar à sobrecarga laboral e, com isso, prejuízos no cumprimento das atribuições previstas ${ }^{18}$. A despeito dos muitos avanços na legislação do PNAE, os resultados sistematizados sugerem que ainda são necessários avanços relacionados à inserção do nutricionista na alimentação escolar, sobretudo na região Norte ${ }^{18}$.

Em um dos artigos analisados no presente estudo $^{6}$ foi verificada irregularidade unânime em todo o território nacional em relação à execução dos CAE, inclusive a assinatura por apenas um conselheiro, podendo comprometer a fidelidade dos dados reportados. Segundo a legislação, a execução falha do Conselho pode ser responsável pela suspensão do repasse de recursos do Fundo Nacional de Desenvolvimento da Educação (FNDE) para o PNAE no município ${ }^{2}$ e todos os membros constituintes do conselho devem assinar o parecer conclusivo da fiscalização do $\mathrm{PNAE}^{8}$. Os CAE têm a responsabilidade de acompanhar e fiscalizar as atividades e os recursos destinados à alimentação escolar, assim como o cuidado com a qualidade e aceitabilidade dos cardápios $^{3,6}$. Assim, as deficiências reportadas podem comprometer o bom funcionamento e o alcance dos objetivos do PNAE, além de poder implicar na suspensão do repasse financeiro dos recursos para o Programa ${ }^{6,17}$. Dessa forma, indica-se a necessidade de ações mais incisivas para uma devida apropriação das atribuições dos Conselhos e o desenvolvimento satisfatório do Programa ${ }^{17}$. Nesse sentido, é necessário considerar que a baixa atuação dos CAE pode estar relacionada à não consolidação de uma rotina de trabalho, o que limita o desenvolvimento das responsabilidades legisladas e inclui a carência de reuniões periódicas e de visitas às escolas e ao almoxarifado, bem como análises insuficientes dos documentos relativos às despesas do Programa ${ }^{30}$.

Em relação à compra de alimentos provenientes da agricultura familiar, os resultados indicam uma baixa adesão dos municípios nesse sentido. Essa situação pode ter explicações em função da necessidade de mecanismos precisos e eficientes, bem como da organização de gestores e agricultores, para a efetivação da normativa; 
e da estrutura insuficiente dos produtores para atender à demanda das escolas ${ }^{17,19,20}$. A não inclusão de alimentos da agricultura familiar na alimentação escolar pode comprometer a oferta de alimentos adequados aos hábitos regionais de cada localidade e prejuízos relacionados à satisfação das necessidades nutricionais ${ }^{2,9,31}$. A compra desses alimentos favorece o desenvolvimento local e proporciona a oportunidade de unir a promoção à saúde com a sustentabilidade ambiental, social, econômica e cultural ${ }^{19}$. A aquisição obrigatória de 30\% de gêneros alimentícios provenientes da agricultura familiar foi determinada pela Lei $11.947^{2} \mathrm{e}$, portanto, deve ser garantida. O incentivo ao consumo de alimentos locais pode caracterizar uma alimentação mais saudável e influenciar negativamente a produção e o consumo de alimentos processados pela indústria, que se caracterizam pelo baixo valor nutricional ${ }^{32}$.

A atuação intersetorial e pedagógica, a gestão municipal e a atuação das merendeiras foram temas pouco abordados. Para a efetiva execução do PNAE, o trabalho intersetorial é considerado uma ação essencial e estratégica ${ }^{16,28}$. Por sua vez, estabelecer novos paradigmas de gestão e de práticas pedagógicas no contexto do PNAE constitui um alicerce para a instituição escolar responder às necessidades dos escolares ${ }^{28}$. As dificuldades sugeridas por meio dos estudos desta revisão relacionadas ao desenvolvimento de projetos edu- cativos refletem inadequações no planejamento e na gestão do Programa ${ }^{16}$. A atuação das merendeiras é essencial ao Programa, uma vez que as mesmas interagem diretamente com os alunos, estabelecendo vínculos que possibilitam conhecer suas preferências alimentares e dar orientações sobre hábitos alimentares saudáveis ${ }^{32}$. Assim, a importância de avaliações do PNAE, que contemplem esses parâmetros, está relacionada à oportunidade de alertar aos gestores sobre as dificuldades nas ações desenvolvidas.

De uma maneira geral, observa-se na literatura sistematizada que, apesar da garantia do repasse financeiro, há várias discrepâncias em relação à execução do PNAE conforme rege as legislações ${ }^{2,8}$. Os dados aqui apresentados mostram a necessidade de uma maior atenção ao Programa, de maneira a garantir uma alimentação escolar dentro de princípios que promovam a segurança alimentar e nutricional. $\mathrm{O}$ desenvolvimento de novos estudos avaliativos sobre o Programa é fundamental para o fornecimento de subsídios aos gestores públicos para aprimorar a execução do PNAE.

É pertinente ressaltar que limitações deste estudo podem advir da consulta a apenas duas bases de dados para a identificação dos estudos. Por outro lado, a inexistência de um descritor específico sobre o tema pode influenciar a eficiência da busca bibliográfica.

\section{Colaboradores}

D Figueroa Pedraza participou da concepção do artigo, revisão bibliográfica, análise e interpretação dos dados, redação e aprovação do artigo. NLS Melo, FA Silva e EMN Araújo participaram da revisão bibliográfica, análise e interpretação dos dados, redação e aprovação do artigo. 


\section{Referências}

1. Brasil. Constituição da República Federativa do Brasil de 1988. Diário Oficial da União 1988; 5 out.

2. Brasil. Lei no 11.947 , de 16 de junho de 2009. Dispõe sobre o atendimento da alimentação escolar e do Programa Dinheiro Direto na Escola aos alunos da educação básica; altera as Leis nos 10.880, de 9 de junho de 2004, 11.273, de 6 de fevereiro de 2006, 11.507, de 20 de julho de 2007; revoga dispositivos da Medida Provisória no 2.178-36, de 24 de agosto de 2001, e a Lei 8913 , de 12 de julho de 1994; e dá outras providências. Diário Oficial da União 2009; 17 jun.

3. Gabriel CG, Machado MS, Scmitz BAS, Corso ACT, Caldeiras GV, Vasconcelos FAG. Conselhos Municipais de Alimentação Escolar em Santa Catarina: caracterização e perfil de atuação. Cien Saude Colet 2013; 18(4):971-978.

4. Machado PMO, Machado MS, Schmitz BAS, Corsa ACT, González-Chica DA, Vasconcelos FAG. Caracterização do Programa Nacional de Alimentação Escolar no Estado de Santa Catarina. Rev Nutr 2013; 26(6):715725.

5. Peixinho AML. A trajetória do Programa Nacional de Alimentação Escolar no período de 2003-2010: relato do gestor nacional. Cien Saude Colet 2013; 18(4):909916.

6. Bandeira LM, Chagas CMS, Gubert MB, Toral N, Monteiro RA. Análise dos pareceres conclusivos dos Conselhos de Alimentação Escolar sobre a execução do Programa Nacional de Alimentação Escolar. Rev Nutr 2013; 26(3):343-351.

7. Agência Nacional de Vigilância Sanitária (ANVISA). Resolução RDC no 216, de 15 de setembro de 2004. Dispõe sobre Regulamento Técnico de Boas Práticas para Serviços de Alimentação. Diário Oficial da União 2004; 16 set.

8. Brasil. Resolução CD/FNDE n 38 , de 16 de julho de 2009. Dispõe sobre o atendimento da alimentação escolar aos alunos da educação básica no Programa Nacional de Alimentação Escolar - PNAE. Diário Oficial da União 2009; 17 jul.

9. Instituto Brasileiro de Geografia e Estatística (IBGE). Pesquisa Nacional de Saúde do Escolar: 2009. Rio de Janeiro: IBGE; 2010.

10. Brasil. Resolução/CD/FNDE no 26, 17 de junho de 2013. Dispõe sobre o atendimento da alimentação escolar aos alunos da educação básica no âmbito do Programa Nacional de Alimentação Escolar - PNAE. Diário Oficial da União 2013; 18 jun.

11. Reis CEG, Vasconcelos IAL, Barros JFN. Políticas públicas de nutrição para o controle da obesidade infantil. Rev Paul Pediatr 2011; 29(4):625-633.

12. Silva CA, Marques LA, Bonomo E, Bezerra OMA, Corrêa MS, Passos LSF, Souza AA, Barros BF, Souza DMS, Reis JA, Andrade NG. O Programa Nacional de Alimentação Escolar sob a ótica dos alunos da rede estadual de ensino de Minas Gerais, Brasil. Cien Saude Colet 2013; 18(4):963-969.

13. Gabriel CG, Goulart G, Calvo MC. Gestão municipal do Programa Nacional de Alimentação Escolar nas capitais da região Sul do Brasil. Rev Nut 2015; 28(6):667680 .
14. Gonçalves HVB, Cunha DT, Stedefeldt E, Rosso VV. Family farming products on menus in school feeding: a partnership for promoting healthy eating. Cien Rural 2015; 45(12):2267-2273.

15. Cunha DT, Gonçalves HVR, Lima AFA, Martins PA, Rosso VV, Stedefeldt E. Regional food dishes in the Brazilian National School Food Program: Acceptability and nutritional composition. Rev Nutr 2014; 27(4):423-434.

16. Gabriel CG, Calvo MCM, Vasconcelos AG, Lacerda JT, Freitas FT, Schmitz BAS. Avaliação da gestão municipal do Programa Nacional de Alimentação Escolar nos maiores municípios de Santa Catarina, Brasil. Cad Saude Publica 2014; 30(9):2017-2023.

17. Bezerra OMPA, Bonomo E, Silva CAM, Correa MS, Souza AA, Santos PCT, Silva ML, Almeida MR, Carvalho KP, Marques LA, Souza DMS. Promoção da aquisição de produtos da agricultura familiar para a alimentação escolar em Territórios da Cidadania de Minas Gerais e Espírito Santo. Rev Nutr 2013; 26(3):335-342.

18. Chaves LG. Reflexões sobre a atuação do nutricionista no Programa Nacional de Alimentação Escolar no Brasil. Cien Saude Colet 2013; 18(4):917-926.

19. Saraiva EB, Silva APF, Sousa AA, Cerqueira GF, Chagas CMS, Toral N. Panorama da compra de alimentos da agricultura familiar para o Programa Nacional de Alimentação Escolar. Cien Saude Colet 2013; 18(4):927936.

20. Gabriel CG, Costa LCF, Calvo MCM, Vasconcelos FAG Planejamento de cardápios para escolas públicas municipais: reflexão e ilustração desse processo em duas capitais brasileiras. Rev Nutr 2012; 25(3):363-372.

21. Toledo MTT, Abreu MN, Lopes ACS. Adesão a modos saudáveis de vida mediante aconselhamento por profissionais de saúde. Rev Saude Publica 2013; 47(3):540548.

22. Mello MVO, Bernardelli Junior R, Menossi BRS, Vieira FS. Comportamentos de risco para a saúde de estudantes da Universidade Estadual do Norte do Paraná (Brasil) - uma proposta de intervenção online. Cien Saude Colet 2014; 19(1):59-164.

23. Ribeiro GN, Silva JBL. A alimentação no processo de aprendizagem. Rev Eventos Pedagógicos 2013; 4(2):7785.

24. Bertin LR, Malkowski J, Zutter LCI, Ulbrich AZ. Estado nutricional, hábitos alimentares e conhecimentos de nutrição em escolares. Rev Paul Pediatr 2010; 28(3):303-308.

25. Oliveira MC, Vassimon HS. Programa Nacional de Alimentação Escolar e sua aceitação pelos alunos: uma revisão sistemática. Investigação 2012; 12:4-10.

26. Sampaio NV, Machado NMV, Soares MCV, Pinto ARR. Alimentação na escola e autonomia- desafios e possibilidades. Cien Saude Colet 2013; 18(4):937-945.

27. Carvalho AS, Oliveira e Silva D. Perspectivas de segurança alimentar e nutricional no Quilombo de Tijuaçu, Brasil: a produção da agricultura familiar para a alimentação escolar. Interface (Botucatu) 2014; 18(50):521-532. 
28. Brasil. Ministério da Educação (MEC). O papel do Nutricionista no Programa Nacional de Alimentação Escolar (PNAE) - Manual de instruções operacionais para nutricionistas vinculados ao PNAE. Brasília: MEC; 2012.

29. Brasil. Conselho Federal de Nutricionistas. Resolução/ CFN no 465, de 23 de agosto de 2010. Dispõe sobre as atribuições do Nutricionista, estabelece parâmetros numéricos mínimos de referência no âmbito do Programa de Alimentação Escolar (PAE) e dá outras providências. Diário Oficial da União 2010; 16 jun.

30. Nascimento JLR. A atuação dos Conselhos Municipais de Alimentação Escolar: análise comparativa entre o controle administrativo e o controle público [monografia]. Belo Horizonte: Universidade Federal de Minas Gerais; 2010.

31. Soares P, Martinelli SS, Melgarejo L, Davó-Blanes MC, Caballi SB. Potencialidades e dificuldades para o abastecimento da alimentação escolar mediante a aquisição de alimentos da agricultura familiar em um município brasileiro. Cien Saude Colet 2015; 20(6):1891-1900.

32. Fernandes AGS, Fonseca AABC, Silva AA. Alimentação escolar como espaço para educação em saúde: percepção das merendeiras do município do Rio de Janeiro. Cien Saude Colet 2014; 19(1):39-48.

Artigo apresentado em 14/04/2016

Aprovado em 16/08/2016

Versão final apresentada em 18/08/2016 